\title{
Safe and smart savings products for vulnerable adolescent girls in Kenya and Uganda: Evaluation report
}

\author{
Karen Austrian \\ Population Council \\ Eunice N. Muthengi \\ Population Council
}

Follow this and additional works at: https://knowledgecommons.popcouncil.org/departments_sbsr-pgy

Part of the Demography, Population, and Ecology Commons, Family, Life Course, and Society Commons, Gender and Sexuality Commons, International Public Health Commons, and the Medicine and Health Commons How does access to this work benefit you? Let us know!

\section{Recommended Citation}

Austrian, Karen and Eunice N. Muthengi. 2013. "Safe and smart savings products for vulnerable adolescent girls in Kenya and Uganda: Evaluation report." Nairobi: Population Council. 


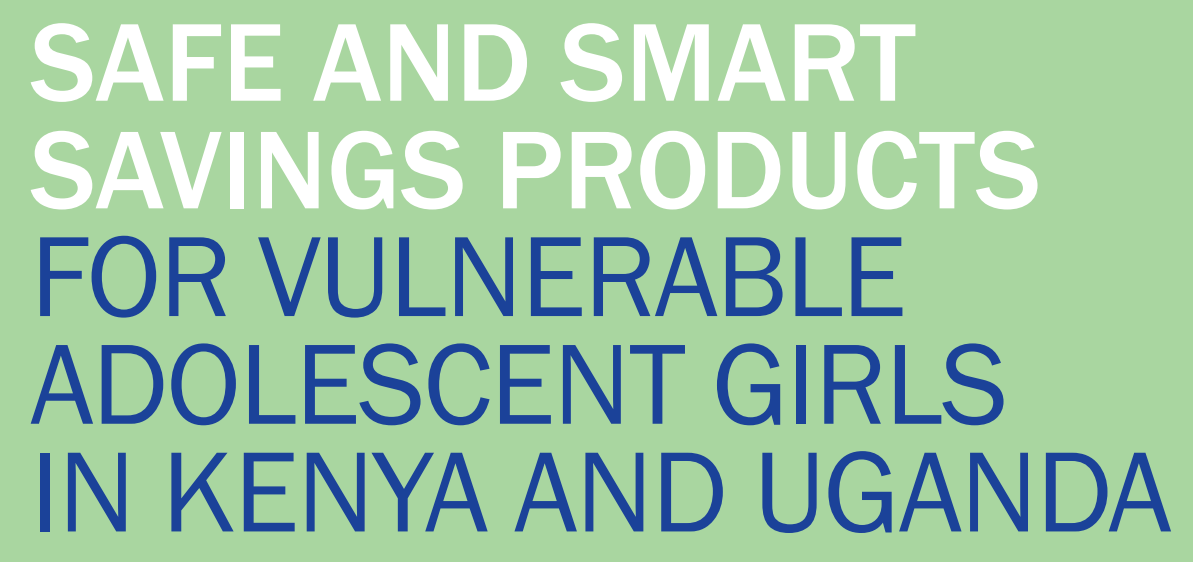

IN KENYA AND UGANDA

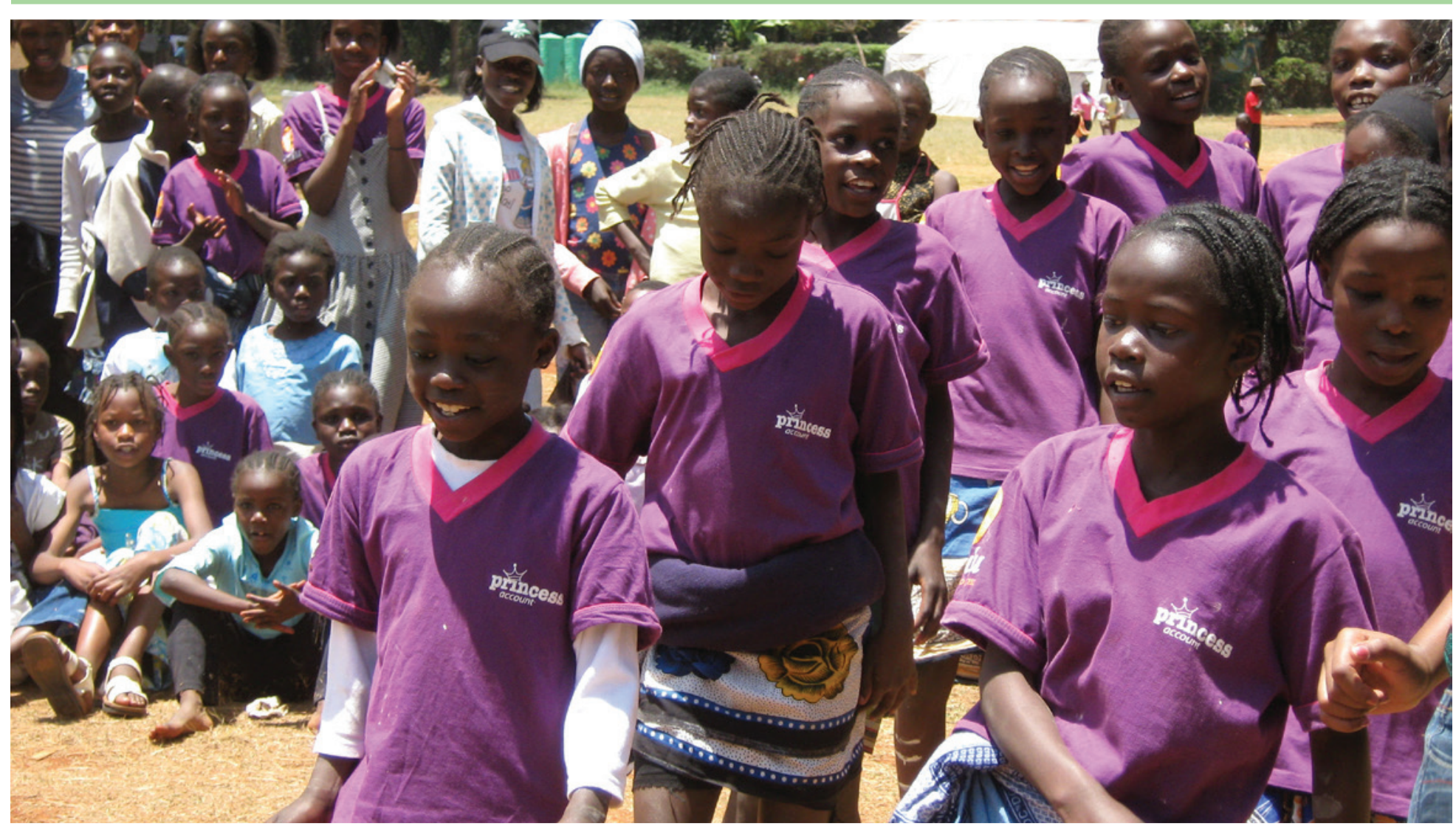

KAREN AUSTRIAN EUNICE MUTHENGI 


\section{(2) Population Council}

The Population Council confronts critical health and development issues-from stopping the spread of HIV to improving reproductive health and ensuring that young people lead full and productive lives. Through biomedical, social science, and public health research in 50 countries, we work with our partners to deliver solutions that lead to more effective policies, programmes, and technologies that improve lives around the world. Established in 1952 and headquartered in New York, the Council is a nongovernmental, nonprofit organization governed by an international board of trustees.

Population Council

P.O. Box 17643-00500

Nairobi, Kenya

Tel: (254) 202713480

Fax: (254) 202713479

www.popcouncil.org

Suggested citation: Austrian, K. and E. Muthengi. 2013. "Safe and Smart Savings Products for Vulnerable Adolescent Girls in Kenya and Uganda: Evaluation Report." Nairobi: Population Council..

Photos by Karen Austrian.

(c) 2013 The Population Council, Inc. 


\section{TABLE OF CONTENTS}

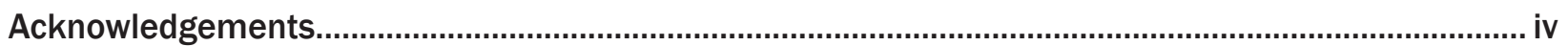

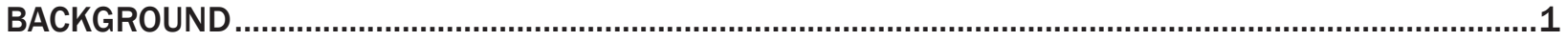

PROGRAM MODEL - Safe and Smart Savings Products for Vulnerable

Adolescent Girls in Kenya and Uganda ...........................................................................................

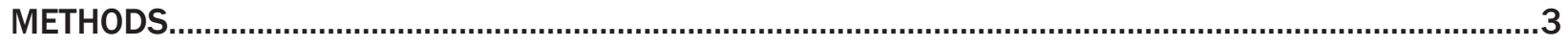

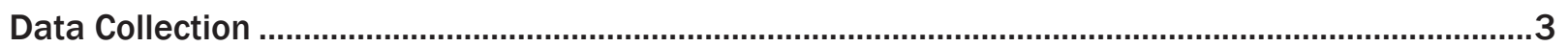

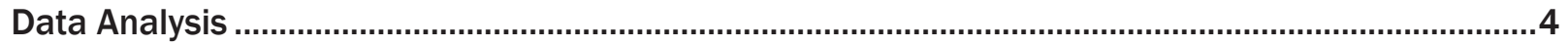

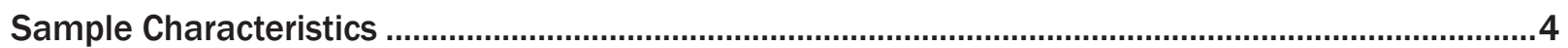

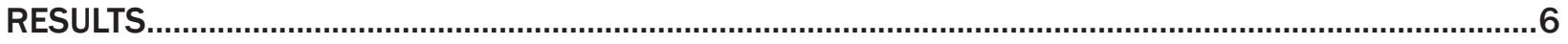

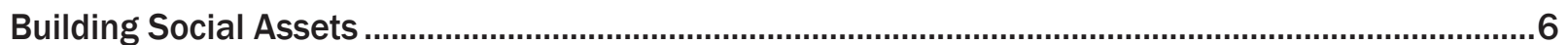

Providing Critical Reproductive Health Information ....................................................................

Empowering Girls with Financial Skills and Economic Assets ........................................................ 10

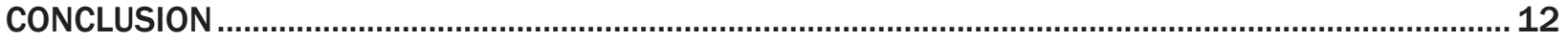


$\mathrm{T}$ his study would not have been possible without the hard work of the diverse program and research teams - consisting of many individuals dedicated to improving lives for vulnerable adolescent girls. At MicroSave Consulting: Corrinne Ngurukie, Angela Wambugu and Elizabeth Kariuki in Kenya and Flavia Nakamatte and Doreen Ahimbisibwe in Uganda. At the Population Council, Dennitah Ghati in Kenya and Julie Bayiga in Uganda played a key role in supporting program implementation as well as research activities. In addition, we thank K-Rep Bank; Faulu Kenya, DTM; Finance Trust; and FINCA-Uganda, our four financial institution partners, for being willing to go on this journey with us and experiment with new, and often challenging, financial products to enhance the lives of vulnerable girls. Staff at these financial institutions, including the managing directors, senior management, branch managers and field officers, worked tirelessly and made this project a success. We also thank all the mentors who worked with the girls on a weekly basis, as well as the research assistants who collected the data over the years.

The authors thank the following donors for their support: Nike Foundation and the Financial Education Fund. The Nike Foundation, as the initial donor, took a risk in investing in previously untested interventions for girls and we believe that investment paid off.

Finally, we are grateful to the adolescent girls who shared their thoughts and experiences with us and thank them for participating in the program and enriching our work with their drive and energy to make changes in their own lives. 
A $s$ part of the Council's work with adolescent girls in Kenya, two different projects led to the decision to engage in the development of savings accounts for girls. The first, Tap and Reposition Youth (TRY), worked to adapt adult micro-credit models for adolescent girls. Two key lessons from this project were that the girls wanted to be able to save independent from the collateral on their loans and that they valued the social support component (i.e., making friends and having a mentor) as much as, if not more than, the financial service they were receiving. The second set of projects were focused on providing health education and leadership training to girls, but it became clear that without addressing the poor economic situation of the girls, they were often unable to prevent behaviors that put their health at risk. This led first to the integration of financial education (i.e., teaching girls about money management, savings, budgeting, setting financial goals, etc.) into the health programs. As these programs became quite popular, girls were saving, but only informal mechanisms were available to them and they expressed a desire for safe and secure places to put their savings.

In June 2008 the Population Council and MicroSave started the Safe and Smart Savings Products for Vulnerable Adolescent Girls project. The Council, together with MicroSave Consulting, Ltd, worked closely with the financial institutions to design girl-friendly savings accounts based on market research that was conducted with girls to understand their cash flow and financial service needs. Once the accounts were designed, concepts tested with girls, and the bank staff trained and ready to launch the product, program activities would begin. Girls were recruited at community level, formed into groups, and then facilitated to open accounts. The intervention ran for approximately 18 months. Throughout the program period Population Council provided technical support, especially in the area of the safe spaces groups and training. MicroSave provided support on the operation of the accounts.
At the time, the only "child accounts" that existed were operated by the guardian in the name of a childnot an account that adolescents could operate themselves. Key findings from initial market research were that 1) girls had money; 2) if an appropriately designed savings account was available, girls would save their money in them; and 3) girls wanted health and social activities alongside the opportunity to save. Based on the market research and prior experience with developing programs for adolescent girls, a product concept for a group-based savings account was developed, in which the group model was used to address the legal

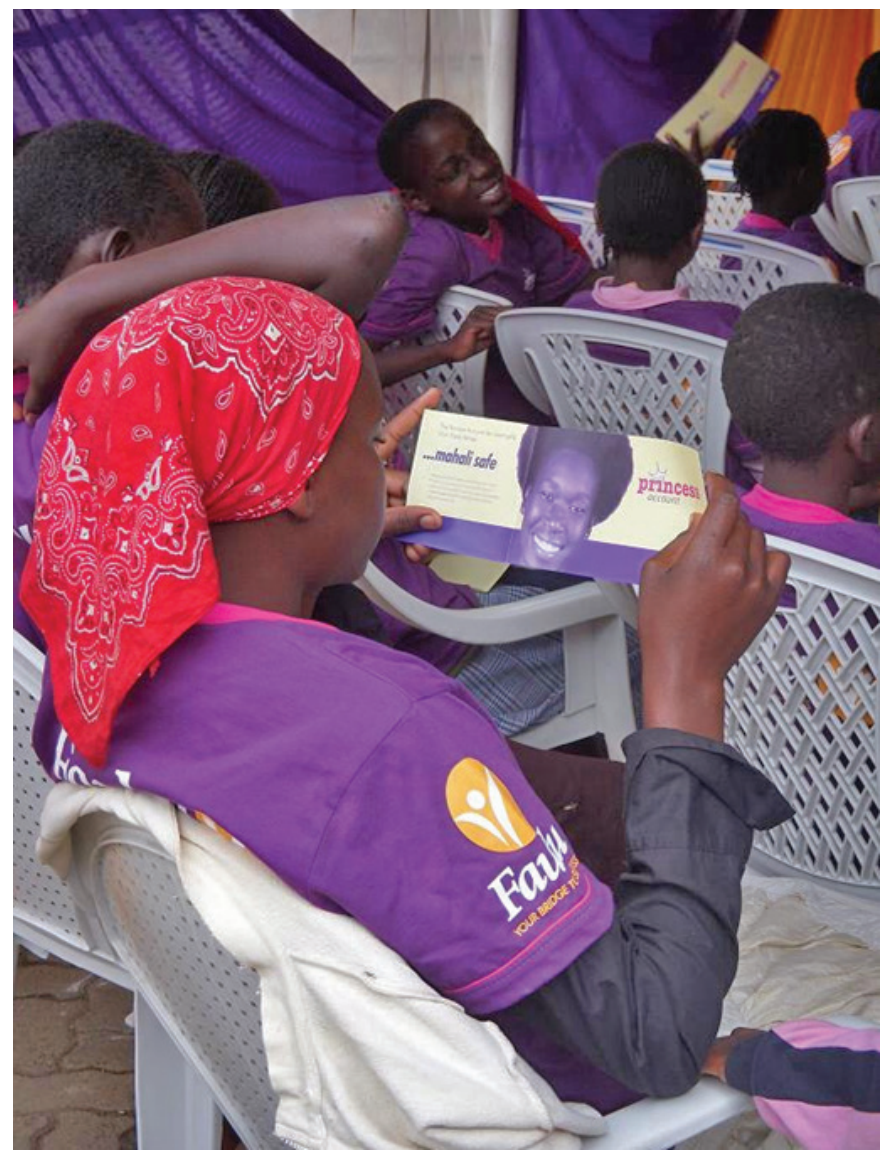


constraints of minors not being able to hold individual accounts, as well as providing the girls with access to the 'Safe Spaces' model of programming, building their social networks.

Two financial institutions were identified in Kenya (K-Rep Bank and Faulu Kenya, DTM) and two in Uganda (FINCA-Uganda and Finance Trust) because they: had an interest in development of a girls savings account, had commitment from the top management levels for this type of project, and had the right systems in place to deliver it.

After a 3-4 month pilot preparation process in each country in which the product design was finalized, the products were branded, staff was hired and trained, and the systems were set up at the financial institutions, the pilot test was launched with a target of 500 girls for each financial institution. Each financial institution piloted the account in two branches: in Kenya both branches were operating in the Kibera slum in Nairobi; for FINCA the pilot test branches were in Katwe and Kawempe; and for Finance Trust the pilot test branches were in Katwe and Kalerwe (all slum areas in Kampala). The pilot period lasted approximately one year during which the savings and group activity was monitored and adjustments to the model made along the way.

Over the course of the one-year pilot period, over 2,000 girls participated across the four financial institutions. These are the girls who participated in the evaluation. 
T he overall aim of the project was to develop, pilot test, and roll-out individual savings accounts offered to girls belonging to girls groups, with four financial institutions, two in Kenya and two in Uganda. These accounts combine methods in designing financial products for low-income clients, and a 'safe space' program model that is supportive for adolescent girls. The overall aim of the program evaluation plan was to understand the social, economic, and health effects of participating in these activities on the girls themselves.

The Safe and Smart Savings Products for Vulnerable Adolescent Girls (SSSPVAG) program consisted of three main activities. The first was weekly group meetings with a female mentor. Each group was made up of 15-25 girls aged 10-14 or aged 15-19. Groups were built on the Council's Safe Spaces model, which includes: 1) a physical safe space where girls can meet regularly in their community; 2) a group of same-sex friends their age living in the same community; and 3) a mentor who is a young woman from the community who meets with the girls regularly. During group meetings, girls conducted savings activities and received training on financial education and health. Group meetings were supplemented with fun days and parents meetings.

The second activity was financial education. A financial education curriculum was developed and tested. It included 16 simplified sessions that are accompanied by a savings diary. Topics included planning for the future, having savings goals, making savings plans, controlling spending, knowing the difference between needs and wants, financial negotiations, and resolving conflicts about money.

The third activity was an individual savings account. The account had either no or a very low opening balance and no transaction or monthly fees. These were not contract accounts-meaning that girls could deposit as much or as little as they wanted, at the time intervals that they choose. In addition to the group mentor (social mentor), girls were required to choose a financial mentor who was above the age of 18 to serve as a co-signatory on the account. The financial mentor needed to be present together with the girl for account opening and withdrawals, but girls could deposit on their own at the branch. Girls were rewarded for regular depositing, attendance and participation through incentives such as t-shirts, home banks (piggy bank), and savings photo identification cards.

\section{METHODS}

\section{Data Collection}

Preparations for the baseline survey in Kenya began in November 2008 with the drafting of the baseline tool, which was reviewed internally at the Council and by the Nike Foundation/ICRW. The survey was then translated into Kiswahili. In Uganda, the questionnaire was adapted and translated into Luganda in August 2009. In both countries, teams of interviewers and supervisors were trained for two days on interviewing skills and the survey instrument itself. The survey was pilot-tested and revised based on feedback from the interviewers. In the field, completed surveys were reviewed for accuracy by the field interviewers. Data were entered on an ongoing basis by the Population Council-Kenya data entry staff. Data cleaning and analysis was completed by the Council project staff.

It was decided to interview every girl who opened a savings account with each financial institution (with the goal of 500 girls per institution). As groups were being formed, the field officers informed the Council staff of the time and location of the introductory meetings, and the appropriate numbers of interviewers were assigned. In addition, a sample of girls residing in comparison 
areas was interviewed. They were recruited from the two slums in Nairobi most similar to Kibera and the Nakawa slums In Kampala, also most similar to the areas where the program was being implemented. Girls in the comparison groups were recruited using the three most common methods through which the girls in the program were recruited: daughters of existing clients in the financial institutions, through community youth organizations and churches, and word of mouth from girl to girl. Data were collected in a rolling fashion as the girls opened their savings accounts, typically at the second or third group meeting. In Kenya, data collection began in December 2008 and ended in June 2009, while in Uganda data collection began in October 2009 and ended in May 2010.

A similar recruitment and training of interviewers process was followed for the pilot endline data collection. Using the contact information collected at baseline, as well as the help of the financial institution, field officers and mentors, girls interviewed at baseline were identified and interviewed a second time. In Kenya, endline data collection took place between December 2009 and March 2010, while in Uganda data collection occurred between December 2010 and March 2011.

At baseline, a total of 1,473 girls were interviewed in Kenya and 1,564 girls were interviewed in Uganda. During the second round of interviews, $82 \%$ of Kenyan girls $(n=1,210)$ and $74 \%$ of Ugandan girls $(n=1,159)$ were re-interviewed at endline.

A qualitative study was conducted during the Pilot phase in 2008 and during the rollout phase in 2011. In both Kenya and Uganda, focus groups and in-depth interviews were conducted with program participants, parents, mentors, and project staff. A total of 185 girls aged 10 to 14 and 154 girls aged 15 to 19 participated in focus groups discussions regarding their feelings about the program, their use of savings accounts, the usefulness of various program components, and practical applications of information learned. In Uganda 12 girls who did not participate in safe spaces groups were also interviewed.

\section{Data Analysis}

The final sample for this report included 899 girls in Kenya and 1,062 girls in Uganda who were successfully matched across the two survey waves and were below the age of 20 at baseline. Data for the two financial groups in Kenya (Faulu and K-Rep) and in Uganda (FINCA and Finance Trust) were combined and compared with the respective comparison groups. Bi-variate analyses were conducted by comparing means (continuous variables) and proportions (categorical variables) across the two treatment groups (intervention versus control), for the two waves of data (baseline and endline). For the demographic characteristics, we tested differences across the treatment groups at follow-up using the Pearson's Chi-Square and Anova tests. For all other indicators, we utilized the study design to examine the change in knowledge, attitudes and behaviors from baseline to endline, for intervention groups compared to comparison groups. We ran separate multivariate random-intercept models (logistic for categorical variables and linear regression for continuous variables) for each indicator, controlling for the respondent's age. These models include an interaction term between the treatment group (intervention versus comparison) and the time period (baseline versus endline), and dummy variables for the treatment group (comparison $=$ reference group) and the time period (baseline $=$ reference group). Estimates for the interaction terms obtained from these models represent the difference in the outcomes between intervention and comparison groups over time. These models also control for unobserved characteristics of individuals that might be correlated with the outcome. For Kenya, models control for age and religion and for Uganda, models control for age, religion and socioeconomic status (number of assets). In Uganda, the multivariate analyses examining the effects of being in a safe-spaces group include the same variables as above, but there are two treatment groups and two interaction terms for "group" by time period, and "no group" by time period.

\section{Sample Characteristics}

Sample characteristics were examined at baseline, comparing girls in intervention groups with girls in comparison groups (see Table 1). The Kenyan sample included 615 girls who participated in the intervention and 284 girls in the comparison group. The Ugandan sample included 750 girls in the intervention group and 312 girls in the comparison group. Girls in the intervention groups were significantly younger than girls in the comparison groups. More than three-quarters of intervention participants in Kenya were below the age of 15 (78\%), compared to 65 percent of girls in the comparison group. In Uganda, 72 percent of intervention participants and 56 percent of girls residing in the comparison area were below the age of 15 . Age differences were closely associated with significant differences in education status in Kenya; there were no significant differences in educational status in Uganda. Intervention participants in Kenya, who were younger in age, were more likely to be in primary school (80\%) than girls in the comparison group (66\%).

Kenyan girls were significantly more likely to be living with both parents (58\% intervention, $60 \%$ comparison) than Ugandan girls (42\% intervention, $44 \%$ comparison). In Uganda, about a third of girls were living with only one parent. Intervention girls in Uganda were more likely to be living with only a father ( $8 \%$ intervention, $4 \%$ comparison), while comparison girls were more likely to be living with only a mother (33\% comparison, $27 \%$ intervention). 
TABLE 1 Sample Characteristics in Intervention and Comparison Areas at Baseline

\begin{tabular}{|c|c|c|c|c|}
\hline & \multicolumn{2}{|c|}{ KENYA } & \multicolumn{2}{|c|}{ UGANDA } \\
\hline & $\begin{array}{l}\text { Intervention } \\
\quad(n=615)\end{array}$ & $\begin{array}{r}\text { Comparison } \\
(n=284)\end{array}$ & $\begin{array}{l}\text { Intervention } \\
(n=750)\end{array}$ & $\begin{array}{r}\text { Comparison } \\
(n=312)\end{array}$ \\
\hline \multicolumn{5}{|l|}{ Age } \\
\hline $10-14$ & $78 \%$ & $65 \%^{* * *}$ & $72 \%$ & $56 \%{ }^{* * *}$ \\
\hline $15-19$ & $22 \%$ & $35 \%$ & $28 \%$ & $44 \%$ \\
\hline \multicolumn{5}{|l|}{ Religion } \\
\hline Catholic & $20 \%$ & $32 \%^{* * *}$ & $40 \%$ & $24 \%$ *** \\
\hline Protestant & $55 \%$ & $68 \%$ & $34 \%$ & $36 \%$ \\
\hline Muslim & $25 \%$ & $1 \%$ & $25 \%$ & $39 \%$ \\
\hline Other & $1 \%$ & $0 \%$ & $0 \%$ & $1 \%$ \\
\hline Ever married & $0 \%$ & $0 \%$ & $1 \%$ & $1 \%$ \\
\hline \multicolumn{5}{|l|}{ Educational status: } \\
\hline Not in school & $5 \%$ & $5 \%{ }^{* * *}$ & $5 \%$ & $10 \%$ \\
\hline Primary school & $80 \%$ & $66 \%$ & $65 \%$ & $46 \%$ \\
\hline Secondary school & $16 \%$ & $27 \%$ & $30 \%$ & $44 \%$ \\
\hline University & $0 \%$ & $2 \%$ & $0 \%$ & $1 \%$ \\
\hline \multicolumn{5}{|l|}{ Living arrangements: } \\
\hline Both parents & $58 \%$ & $60 \%$ & $42 \%$ & $44 \%$ ** \\
\hline Mother only & $24 \%$ & $21 \%$ & $27 \%$ & $33 \%$ \\
\hline Father only & $4 \%$ & $2 \%$ & $8 \%$ & $4 \%$ \\
\hline Neither parent & $15 \%$ & $17 \%$ & $23 \%$ & $19 \%$ \\
\hline \multicolumn{5}{|l|}{ Socio-economic status } \\
\hline \multicolumn{5}{|l|}{ Household has: } \\
\hline Electricity & $75 \%$ & $77 \%$ & $54 \%$ & $69 \%^{* * *}$ \\
\hline Radio & $75 \%$ & $71 \%$ & $65 \%$ & $78 \%$ *** \\
\hline Television & $64 \%$ & $62 \%$ & $50 \%$ & $64 \%{ }^{* * *}$ \\
\hline Telephone/mobile phone & $94 \%$ & $92 \%$ & $90 \%$ & $96 \%{ }^{* * *}$ \\
\hline $\begin{array}{l}\text { Mean no. of assets (electricity, bed, } \\
\text { phone, radio, TV) }\end{array}$ & 4.0 & 4.0 & 3.5 & $4.0^{* * *}$ \\
\hline Girl owns at least one asset herself & $8 \%$ & $7 \%$ & $19 \%$ & $33 \%$ *** \\
\hline \multicolumn{5}{|l|}{ Identification } \\
\hline Girls with photo ID & $8 \%$ & $13 \%{ }^{*}$ & $41 \%$ & $56 \%$ *** \\
\hline Girls with photo ID (age 18+) & $29 \%$ & $24 \%$ & $64 \%$ & $76 \%$ \\
\hline \multicolumn{5}{|l|}{ Literacy } \\
\hline Read easily & $70 \%$ & $72 \%$ & $53 \%$ & $60 \%$ \\
\hline Read with difficulty & $28 \%$ & $26 \%$ & $40 \%$ & $35 \%$ \\
\hline Cannot read at all & $2 \%$ & $2 \%$ & $7 \%$ & $5 \%$ \\
\hline
\end{tabular}

$* * * p<0.001 ; * * p<0.01 ; * p<0.05$.

Once these categories were combined to compare girls living with one parent, versus no parent, versus both parents, there were no significant differences in living arrangements between treatment groups.

Significant religious differences were observed in both countries. About a quarter of Kenyan intervention girls were Muslims (25\%) compared to only 1 percent of comparison girls. In Uganda, comparison girls were more likely to be Muslim (39\%) than intervention girls (25\%), while intervention girls were more likely to be Catholic (40\% intervention, 24\% comparison).
Kenyan girls in both treatment groups were similar in terms of socioeconomic status. At least three-quarters of households had electricity and more than nine out of ten households owned a phone or a mobile phone. For Uganda, comparison girls were better-off than intervention participants in regards to household ownership of assets. For example, more than two-thirds of households in the comparison group had electricity (69\%) compared to half $(54 \%)$ of households in the intervention group. The majority of Ugandan girls above the age of 17 had some form of photo identification, compared to a quarter of Kenyan girls. 


\section{RESULTS}

\section{Building Social Assets}

Based on a global body of work with adolescent girls, the Council has developed and promoted the Safe Spaces model, a program platform that includes three critical components: 1) a physical safe space where girls can meet regularly in their community; 2) a group of same-sex friends their age living in the same community; and 3) a mentor who is a young woman from the community who meets with the girls regularly. The SSSPVAG program utilized this model to build girls' social and health assets by enabling them to make friends, form social relationships and expand their social networks. At endline, at least half of girls stated that they had made a new friend within the previous year, that they had a safe place to meet their friends outside of school or a friend's house, and that they had a female mentor in their community other than a parent or teacher. Girls mentioned in the qualitative data that they valued the ability to discuss issues with their mentors and receive guidance and counseling.

"I feel more secure, I know I get a lot of advice from my friends on peer pressure and not to just follow other girls who misbehave, I can share my problems with the group and they help me because I now have many friends that I can trust." -UGANDAN GIRL, AGE 10-14

"I have a bigger circle of friends as a result of being in a group."

-KENYAN GIRL, AGE 10-14
"It [the group] keeps us busy and builds up our self-esteem. We meet many people and get to know other girls. When we now go to school our teachers see we have confidence and it is because we don't fear when we are asked to talk; we can talk with confidence." -KENYAN GIRL, AGE 10-14

Most girls exhibited high levels of self-esteem at endline (see Figure 1). Approximately 90 percent of girls stated they were optimistic that their lives would be better than their parents', 94 percent felt they make good decisions regarding how to manage their money, and more than three-quarters felt as intelligent as most other young people their age. On the other hand, most girls (90\%) wished their parents placed more value on education. Some girls also showed signs of low self-esteem or low hope for their future. One in five Kenya girls (20\%) and one in four Ugandan girls (27\%) stated that they did not have hope for their future, while a third of Kenya girls (38\%) and a quarter of Ugandan girls (26\%) agreed that they sometimes feel worthless. Girls who felt confident making decisions about their money were significantly less likely to say they did not have hope for their future.

Several changes were noted in the multivariate analysis, which compared the changes between baseline and endline for intervention participants and girls in the comparison group. There were no age differences in safety indicators, but there were significant improvements observed among girls who participated in the intervention (see Table 2). In Kenya, about three out of five girls stated that they had somewhere to sleep for the night in the

FIGURE 1 Self-Esteem Indicators among Intervention Participants for Kenya and Uganda at Endline

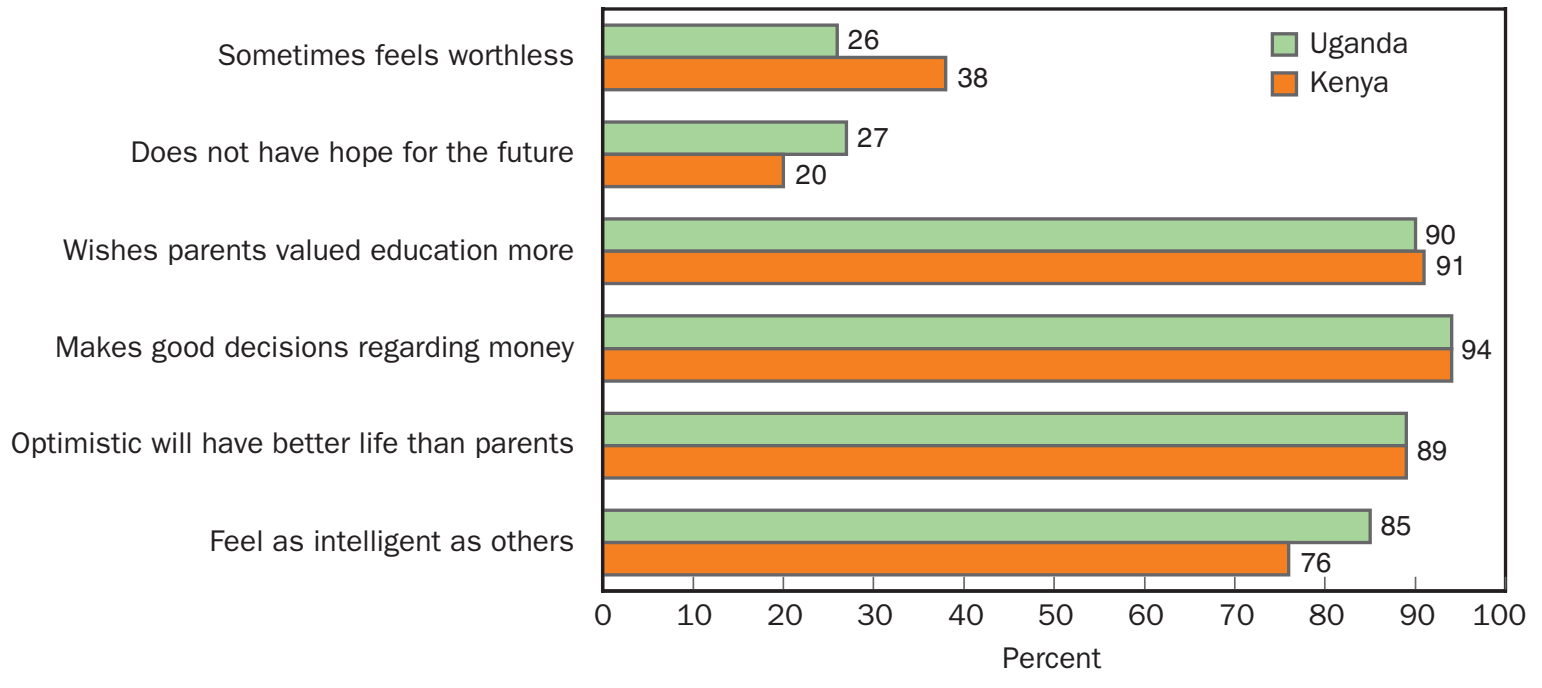


TABLE 2 Changes in Social Well-Being, Networks, and Mobility for Intervention and Comparison Participants in Kenya and Uganda, from Baseline to Endline

\begin{tabular}{|c|c|c|c|c|c|c|c|c|}
\hline & \multicolumn{4}{|c|}{ KENYA } & \multicolumn{4}{|c|}{ UGANDA } \\
\hline & \multicolumn{2}{|c|}{$\begin{array}{l}\text { Intervention } \\
\quad(n=615)\end{array}$} & \multicolumn{2}{|c|}{$\begin{array}{l}\text { Comparison } \\
(n=284)\end{array}$} & \multicolumn{2}{|c|}{$\begin{array}{l}\text { Intervention } \\
\quad(n=750)\end{array}$} & \multicolumn{2}{|c|}{$\begin{array}{c}\text { Comparison } \\
(n=312)\end{array}$} \\
\hline & Baseline & Endline & Baseline & Endline & Baseline & Endline & Baseline & Endline \\
\hline $\begin{array}{l}\text { I have somewhere to sleep for the night } \\
\text { in case of an emergency }\end{array}$ & $59 \%$ & $59 \% * *$ & $60 \%$ & $52 \%$ & $59 \%$ & $60 \%$ & $46 \%$ & $50 \%$ \\
\hline $\begin{array}{l}\text { I feel safe walking around my } \\
\text { neighborhood during the day }\end{array}$ & $82 \%$ & $91 \%$ & $54 \%$ & $67 \%$ & $91 \%$ & $88 \%$ & $84 \%$ & $88 \%$ * \\
\hline $\begin{array}{l}\text { I would be much happier if I lived in } \\
\text { another community }\end{array}$ & $69 \%$ & $66 \%{ }^{* *}$ & $78 \%$ & $87 \%$ & $55 \%$ & $57 \%$ & $53 \%$ & $53 \%$ \\
\hline At I times I feel scared that I will be raped & $69 \%$ & $66 \% *$ & $63 \%$ & $72 \%$ & $55 \%$ & $60 \%$ & $59 \%$ & $67 \%$ \\
\hline $\begin{array}{l}\text { In the past six months, I have been touched } \\
\text { indecently by someone of the opposite sex } \\
\text { in my neighborhood }\end{array}$ & $6 \%$ & $2 \%$ & $9 \%$ & $4 \%$ & $8 \%$ & $10 \%$ * & $11 \%$ & $8 \%$ \\
\hline $\begin{array}{l}\text { In my neighborhood, people of the opposite } \\
\text { sex tease me as I go about my day }\end{array}$ & $44 \%$ & $34 \%$ * & $36 \%$ & $38 \%$ & $22 \%$ & $24 \%$ & $24 \%$ & $21 \%$ \\
\hline I am able to go to local health clinic on my own & $13 \%$ & $24 \% * *$ & $24 \%$ & $28 \%$ & $44 \%$ & $52 \%$ & $42 \%$ & $49 \%$ \\
\hline $\begin{array}{l}\text { I am able to go to youth group/girls group on } \\
\text { my own }\end{array}$ & $46 \%$ & $51 \%$ *** & $41 \%$ & $26 \%$ & $50 \%$ & $67 \%$ & $32 \%$ & $45 \%$ \\
\hline $\begin{array}{l}\text { I need someone's permission before I look } \\
\text { for a job }\end{array}$ & $80 \%$ & $69 \%$ ** & $75 \%$ & $74 \%$ & $90 \%$ & $77 \%$ & $87 \%$ & $77 \%$ \\
\hline
\end{tabular}

case of an emergency at baseline. At endline, there was no change for intervention girls but there was a significant decrease among comparison girls, from 60 percent to 52 percent. Intervention participants felt safer and happier in their neighborhoods than comparison girls. Girls who participated in the intervention were significantly less likely to say that they would be happier living in another community at endline. In addition, intervention girls were significantly less likely to report that they feared getting raped, or had been teased by people of the opposite sex at endline. Generally, intervention girls in the older age group (15-19) were significantly more likely to experience teasing than girls in the younger age group. The intervention was associated with increased independence and mobility for girls. There was a significantly greater increase in the proportion of intervention girls who were able to go to a local clinic alone and able to attend youth group meetings alone from baseline to endline. The proportion of girls who needed permission before looking for a job significantly decreased in the intervention group. For all three indicators, older girls (ages 15-19) were significantly more likely to be independent than younger girls (ages 10-14).

Fewer changes were observed in Uganda. The majority of girls in both intervention and comparison groups reported that they felt safe walking around their neighborhoods during the day. While there was a small decrease in the intervention group (91\% baseline, 88\% endline), there was a small increase in the comparison group. There was no significant age difference for girls who participated in the intervention. For the other indicators of social well-being and mobility, the changes observed in the intervention group were not significantly different from those in the comparison group. One notable effect was a slight increase in the proportion of intervention girls who had been touched indecently by a person of the opposite sex within the previous six months. This decreased from 11 percent to 8 percent in the comparison group, but increased from 8 percent to 10 percent in the intervention group. Older intervention girls (aged 15-19) were significantly more likely to report being touched indecently. However, as shown in Table 4, this increase was only noted among girls who did not participate in safe-spaces groups.

In Uganda, some girls who opened savings accounts were never mobilized into safe-spaces groups because they did not know they had the option to join a group. This program delivery error allowed us to examine differences between girls who had a savings account only and those who participated in safe-spaces groups in addition to the savings accounts. There were no differences between the two groups in terms of socioeconomic characteristics. 
TABLE 3 Changes in Gender-Based Violence Indicators for Ugandan Girls in a Group or Not in a Group, from Baseline to Endline

\begin{tabular}{|c|c|c|c|c|c|c|}
\hline & \multicolumn{2}{|c|}{$\begin{array}{l}\text { Uganda - In a Group } \\
\qquad(n=451)\end{array}$} & \multicolumn{2}{|c|}{$\begin{array}{l}\text { Uganda - No Group } \\
\qquad(n=299)\end{array}$} & \multicolumn{2}{|c|}{$\begin{array}{c}\text { Comparison } \\
(n=312)\end{array}$} \\
\hline & Baseline & Endline & Baseline & Endline & Baseline & Endline \\
\hline $\begin{array}{l}\text { Agrees men rape girls because they can't control } \\
\text { themselves }\end{array}$ & $53 \%$ & $43 \%{ }^{* *}$ & $56 \%$ & $52 \%^{\dagger}$ & $56 \%$ & $61 \%$ \\
\hline Knows girls in neighborhood who have been raped & $26 \%$ & $21 \%$ & $23 \%$ & $27 \%{ }^{*}$ & $27 \%$ & $22 \%$ \\
\hline $\begin{array}{l}\text { In the past six months, has been touched indecently } \\
\text { by someone of the opposite sex in the neighborhood }\end{array}$ & $7 \%$ & $8 \%$ & $7 \%$ & $14 \%{ }^{*}$ & $11 \%$ & $8 \%$ \\
\hline $\begin{array}{l}\text { Is teased by people of the opposite sex in the } \\
\text { neighborhood while going about her day }\end{array}$ & $24 \%$ & $24 \%$ & $19 \%$ & $25 \%{ }^{*}$ & $24 \%$ & $22 \%$ \\
\hline
\end{tabular}

$* * * p<.001 ; * * p<.01 ; * p<.05 ;{ }^{\dagger} p<0.1$

As shown in Table 3, participating in safe-spaces groups was protective against gender-based violence and exploitation. Girls in groups were less likely to agree that men rape girls because they cannot control themselves. While there was also a small decrease for girls who were not in groups, the decrease for the girls in groups $(53 \%$ baseline, $43 \%$ endline) was significantly greater than the decrease for girls not in groups. Girls who participated in groups were less likely to know girls in their neighborhood who had been raped, while this increased for girls not in groups. Similarly, there was no significant change in the proportion of girls in groups who had been touched indecently or teased by males in their neighborhoods, but there was an increase in both of these indicators for girls not in groups. These results highlight the protective nature of safe-spaces groups and the importance of building economic assets in combination with social and health assets to avoid increasing girls' vulnerabilities.

Among girls who participated in groups, there were no significant age differences in regards to the experience of teasing and norms related to rape. However, older girls (aged 15-19) were significantly more likely to report that they and been touched indecently than younger girls (aged 10-14). Among girls who were not in groups, older girls were less likely to agree that men rape girls because they cannot control themselves, but more likely to report that they were teased and touched indecently.

\section{Providing Critical Reproductive Health Information}

During safe spaces groups, girls were provided with critical reproductive health information regarding puberty, hygiene, sexual relationships, HIV/AIDS, unintended pregnancy and family planning. At endline, 5 percent of Kenyan girls and 12 percent of Ugandan girls were sexually experienced. When restricted to girls between the ages of 15 and 19, at least one out of five girls (23\%) and 31 percent of Ugandan girls were sexually experi- enced. Only 40 percent of sexually experienced Kenyan girls wanted to have sex during their first time, compared to 63 percent of Ugandan girls. Approximately 18 percent of Kenyan girls and 34 percent of Ugandan girls reported that they had received money, gifts or services in exchange for sex during their lifetimes. There was some evidence from Uganda that girls who saved regularly (always or usually saved weekly) were less likely to have received gifts or money in exchange for sex than girls who saved irregularly (sometimes or never saved weekly). Because of the small numbers, it was necessary to combine intervention and comparison girls for this analysis. As shown in Figure 2, among girls who were sexually experienced,

\section{FIGURE 2 Proportion of Sexually}

Experienced Girls in Uganda Who Have Ever Received Money or Gifts in Exchange for Sex among Irregular and Regular Savers

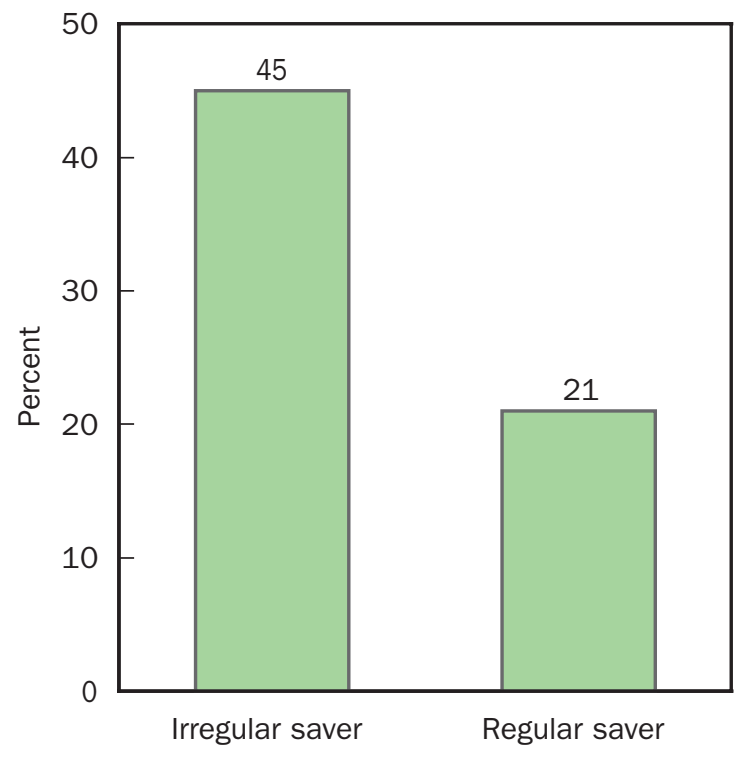


$45 \%$ of irregular savers had engaged in transactional sex as compared to $21 \%$ of girls who saved regularly.

In the qualitative data, girls reported that the reproductive health sessions were helpful in providing them with information about sexual relationships, prevention of unwanted pregnancy and protection against sexually transmitted diseases and HIV.

\section{"HIV/AIDS - lately [it seems] most people are affected by the HIV virus. They taught us the different ways of avoiding contracting with the virus. This is a very common topic among the youths because they are the most victims of HIV so this was very useful to me." -UGANDAN GIRL, AGE 15-19}

Almost all Kenyan and Ugandan girls were knowledgeable about sexual transmission of HIV (96\%) and the ability to protect oneself from HIV infection (98\%). Only 18 percent of girls reported they had ever been worried about getting HIV and about half of girls had actually had an HIV test.

More than two-fifths (46\%) of sexually experienced Kenyan girls and a third (36\%) of sexually experienced Ugandan girls had been pregnant. Yet, only a quarter (25\%) of Kenyan girls and half (55\%) of Ugandan girls were using contraceptives. Almost all girls (96\%) knew about at least one method of contraception. About three-quarters of girls (77\%) knew about condoms, more than half of girls knew about the pill (53\% Kenya, $65 \%$ Uganda), and almost half of girls knew about injectables (45\% Kenya, 50\% Uganda) (see Figure 3). Girls were less knowledgeable about long-term contraceptive methods (i.e. Norplant and IUD) and emergency contraception.
FIGURE 3 Knowledge of Contraceptive Methods among Intervention Participants in Kenya and Uganda at Endline

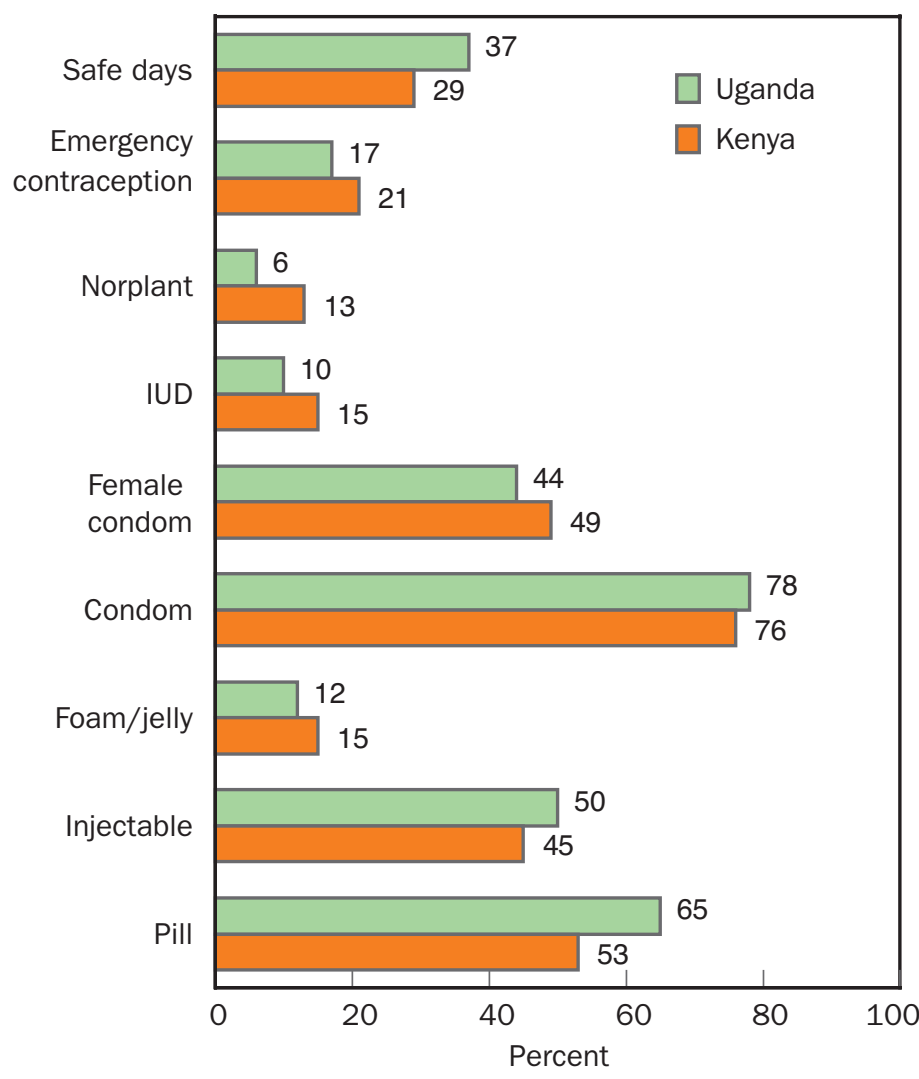

To examine the specific effect of the SSSPVAG program in changing reproductive health knowledge, a few indicators were compared between girls in groups and girls not in groups (see Table 4).

The mean number of HIV transmission methods increased significantly among girls in groups as compared with the comparison group. Girls in groups also had a significantly greater increase in knowledge of sexual transmission of HIV and knowledge of a contraceptive method. The increase in the proportion of girls who had

TABLE 4 Changes in Reproductive Health Indicators for Ugandan Girls in a Group or Not in a Group, from Baseline to Endline

\begin{tabular}{|c|c|c|c|c|}
\hline & \multicolumn{2}{|c|}{$\begin{array}{c}\text { Uganda - In a Group } \\
(n=615)\end{array}$} & \multicolumn{2}{|c|}{$\begin{array}{l}\text { Uganda - No Group } \\
\qquad(n=750)\end{array}$} \\
\hline & Baseline & Endline & Baseline & Endline \\
\hline $\begin{array}{l}\text { Mean number of HIV transmission meth } \\
\text { mentioned }\end{array}$ & 1.49 & $1.94^{* * *}$ & 1.62 & 1.84 \\
\hline Knows HIV can be transmitted sexually & $85 \%$ & $92 \%{ }^{* *}$ & $85 \%$ & $81 \%$ \\
\hline Has had an HIV test & $31 \%$ & $43 \%$ & $36 \%$ & $38 \%$ \\
\hline Knows a contraceptive method & $74 \%$ & $88 \%{ }^{*}$ & $76 \%$ & $76 \%$ \\
\hline
\end{tabular}

$* * * p<0.001 ; * * p<0.01 ; * p<0.05$. 
an HIV test was significantly greater for girls in groups than girls not in groups, but not greater than the increase among comparison girls. Among girls in groups, older girls (aged 15-19) had significantly greater knowledge about HIV and contraceptives and were much more likely to have had an HIV test than younger girls (aged 10-14).

\section{Empowering Girls with Financial Skills and Economic Assets}

Economic independence, especially for girls, is critical for making healthy decisions and translating health knowledge into positive behavior change. As adolescent girls grow and take on more personal and household responsibilities, the need for access to money also increases. In addition, early adolescence is the time to build critical money management skills and develop savings habits that will help adolescents meet short-term goals and daily financial needs, mitigate the effect of household emergencies, and help them plan for a healthier, more stable future.

Girls in Uganda and Kenya reported their most common sources of cash as their mothers (80\%). At least half of girls also received cash from their fathers (54\%) and a third received cash from other relatives (35\%). Only 9 percent of girls obtained cash from casual jobs (i.e. washing clothes, plaiting hair, etc.) and 2 percent from steady jobs. About 17 percent of Kenyan intervention girls and 30 percent of Ugandan intervention girls named their own savings as a source of cash at endline.

More than two-thirds of intervention girls in Kenya (72\%) and Uganda (73\%) had saved money within the previous six months at endline (see Table 5). This was a 53 percent increase from baseline in Kenya, and a 26 percent increase in Uganda. About two-thirds of girls saved using a mix of informal and formal methods. Only 18 percent of Kenyan girls and 9 percent of Ugandan girls saved using formal methods only. Formal methods include bank accounts and savings groups, where informal methods include saving in a box, a mattress, or with friends or relatives.

Ugandan girls deposited money more often into their girls savings accounts than Kenyan girls. They deposited an average of 3.4 times per month, while Kenyan girls deposited an average of 1.9 times per month. The average deposit made each time was Ksh 37 (USD 0.43) for Kenyan girls and Ush 8,633 (USD 3.25) for Ugandan girls, and the total amount in the accounts on average was Ksh 558 (USD 6.5) for Kenyan girls and Ush 39,245 (USD 14.78) for Ugandan girls. This includes about a quarter of Kenyan girls (25\%) and 4 percent of Ugandan girls who had a zero-balance at endline.

About half of Kenyan girls (53\%) and three-quarters of Ugandan girls (77\%) reported that they were saving for a specific reason. When asked what they were saving their money for, the most common responses given by Kenyan girls were education (54\%), personal items (53\%), emergencies (29\%) and household expenses (22\%). Among Ugandan girls, the most common reasons were personal items (67\%), emergencies (52\%), education (36\%) and family business (18\%). More than a quarter of Ugandan girls (29\%) made at least one withdrawal from their accounts, compared to only 7 percent of Kenyan girls. The average withdrawal amount was Ksh 507 (USD 5.9) in Kenya and Ush 35,288 (USD 13.3) in Uganda. Girls mainly spent their savings on personal items (38\% Kenya, 49\% Uganda) and school supplies (34\% Kenya, $21 \%$ Uganda) or school fees (16\% Kenya, 21\% Uganda). Almost one out of five Ugandan girls also spent their savings on clothing (19\%).

In the qualitative data, many girls mentioned that having a savings accounts helped to reduce risks and vulnerability, by enabling them to refuse sexual advances from men, allowing them to be less dependent on men, and helping them to cater for their daily needs and family emergencies. Having a savings account also reduced vulnerability by enabling girls to meet their day-to-day needs and cater for emergencies affecting themselves or their families.

"What attracted me is that saving is very helpful because it minimizes chances of boys taking advantage of us in the disguise of giving us money, thus protects us from acquiring HIV especially from those who come with such intentions." -UGANDAN GIRL, AGE 10-14

"Sometimes a boy can tell you, 'let me hold your hand then I will give you 50 bob [shillings]'...you then tell them, "I have more than that 50 bob you want to give me'." -KENYAN GIRL, AGE 10-14

"I feel good that I have an account in the bank because before accounts were only for adults but now we young ones can save. We go to the bank when adults are there that is good. There are adults who don't even save and have never gone to the bank."

-UGANDAN GIRL, AGE 10-14 


\section{"I can use my saving to pay school fees if mum doesn't have enough." \\ -KENYAN GIRL, AGE 10-14}

\section{"I am now able to buy things like} sanitary towels on my own without asking for money."

-KENYAN GIRL, AGE 15-19

At endline, the majority of respondents answered financial literacy questions correctly. Two-thirds (67\%) of Kenyan intervention participants and more than three-quarters (82\%) of Ugandan girls could correctly name two reasons for saving. Also, at least $90 \%$ of girls correctly named an informal place to save and a formal place to save money. In addition, almost two thirds (65\%) of girls in both Kenya and Uganda could correctly name two bank services.

\section{"You must know why you are saving and must have a plan; don't save just because people are saving."$$
\text { -KENYAN GIRL, AGE 10-14 }
$$

As shown in Table 5, Kenyan girls in the intervention group seemed to do worse on financial literacy indicators at endline as compared to baseline (e.g. having a savings plan). A similar trend was observed in the comparison areas as well. Considering that most girls were below the age of 15 at baseline, it is likely that they did not fully understand what the financial concepts meant, and therefore their initial reports were inaccurate or subject to social desirability bias (responding in a manner that is viewed positively). At endline, when girls were older, more exposed, and more educated, they were more likely to report accurately because they had a better understanding of what a savings plan or budget entails.

The multivariate analysis examined changes in financial literacy and savings behavior between baseline and endline, comparing intervention participants and girls in the comparison group. In Kenya, there was a decrease in the proportion of girls who reported having a savings plan in both the intervention and control groups, and the decrease was significantly higher in the intervention group. On the other hand, intervention girls showed significant improvements over the comparison group in regard to saving money within the previous six months and use of bank services. Older girls (aged 15-19) generally had higher levels of financial literacy compared to younger girls (aged 10-14), but there was no difference in savings behaviors.

The SSSPVAG program had a greater impact on financial indicators in Uganda than in Kenya. There were significant increases in the proportion of intervention girls who had been inside a bank, used a bank service, had a budget for saving money and used a formal method of saving (bank account or saving group). All of these changes were significantly greater than changes in

TABLE 5 Changes in Financial Literacy and Savings Behaviors for Intervention Participants and Comparison Group in Kenya and Uganda, from Baseline to Endline

\begin{tabular}{|c|c|c|c|c|c|c|c|c|}
\hline & \multicolumn{4}{|c|}{ KENYA } & \multicolumn{4}{|c|}{ UGANDA } \\
\hline & \multicolumn{2}{|c|}{$\begin{array}{l}\text { Intervention } \\
(n=615)\end{array}$} & \multicolumn{2}{|c|}{$\begin{array}{c}\text { Comparison } \\
(n=284)\end{array}$} & \multicolumn{2}{|c|}{$\begin{array}{c}\text { Intervention } \\
(n=750)\end{array}$} & \multicolumn{2}{|c|}{$\begin{array}{c}\text { Comparison } \\
(n=312)\end{array}$} \\
\hline & Baseline & Endline & Baseline & Endline & Baseline & Endline & Baseline & Endline \\
\hline $\begin{array}{l}\text { Has a specific reason for saving } \\
\text { money }\end{array}$ & $58 \%$ & $53 \%$ & $48 \%$ & $42 \%$ & $73 \%$ & $77 \%$ & $34 \%$ & $59 \%{ }^{* * *}$ \\
\hline Has a plan for saving money & $74 \%$ & $52 \%$ & $57 \%$ & $43 \%{ }^{*}$ & $43 \%$ & $54 \%$ & $35 \%$ & $40 \%$ \\
\hline $\begin{array}{l}\text { Has a plan or budget for } \\
\text { spending money }\end{array}$ & $42 \%$ & $28 \%$ & $36 \%$ & $24 \%$ & $24 \%$ & $37 \%^{* * *}$ & $29 \%$ & $27 \%$ \\
\hline Has been inside a bank & $21 \%$ & $29 \%$ & $30 \%$ & $37 \%$ & $73 \%$ & $95 \%{ }^{* * *}$ & $31 \%$ & $34 \%$ \\
\hline Has used a bank service & $5 \%$ & $12 \%^{*}$ & $6 \%$ & $6 \%$ & $54 \%$ & $77 \%{ }^{* *}$ & $13 \%$ & $22 \%$ \\
\hline $\begin{array}{l}\text { Saved money in the last six } \\
\text { months }\end{array}$ & $47 \%$ & $72 \%^{*}$ & $22 \%$ & $35 \%$ & $58 \%$ & $73 \%{ }^{* *}$ & $31 \%$ & $34 \%$ \\
\hline $\begin{array}{l}\text { Saved money using a formal } \\
\text { method }\end{array}$ & $61 \%$ & $79 \%$ & $2 \%$ & $6 \%$ & $9 \%$ & $88 \%^{* * *}$ & $8 \%$ & $11 \%$ \\
\hline
\end{tabular}

$* * * p<0.001 ; * * p<0.01 ; * p<0.05$ 
the comparison group. Intervention girls were more likely to be saving for a specific reason at endline, but this increase was smaller than that observed in the comparison group. Compared to younger girls (aged 10-14), older girls (aged 15-19) were significantly more likely to have used a bank service and to have a specific reason for saving and a budget for spending money.

\section{CONCLUSION}

This report describes an evaluation of a savings program designed specifically for vulnerable adolescent girls in slum areas in Kenya and Uganda. Based on the asset building framework, the program was designed to build girls' social, health and economic assets using the Safe Spaces Model. In addition to opening an individual savings account, girls participated in weekly group meetings led by a female mentor, where they gained financial education and reproductive health information. The program was evaluated by comparing data collected at the start of the program with data collected after the one-year pilot period.

There were some notable differences in findings between Kenya and Uganda. These appear to be related to age differences between both intervention groups, as well as differences between the intervention and comparison sites in each country. At endline, less than a third of Kenyan intervention girls were older than age 14 (32\%), compared to half of Ugandan girls (50\%). This could possibly explain why Ugandan girls were more likely to have worked for pay, to have greater knowledge of reproductive health and financial matters, and to have saved money than Kenyan girls.

Another potential explanation is that the Ugandan comparison group appeared to be better off than intervention girls in terms of socioeconomic status (SES), while there were no differences in Kenya. While SES was included as a control variable in the multivariable analysis, the measure used may not have fully captured the differences between groups. This might explain why, for the social mobility indicators, girls in the comparison group in Uganda experienced similar improvements as girls in the intervention group, while comparison girls in Kenya were the same or slightly worse off at endline. While Ugandan girls were more likely to have saved any money at baseline, they were mainly using informal methods. Only 9 percent of girls in Uganda were using formal methods at baseline, compared to 61 percent of Kenyan girls, who were mainly utilizing savings groups. Therefore, the program had a greater impact in Uganda on girls switching from informal to formal methods, and utilizing bank services.

Overall, findings from the evaluation of Safe and Smart Savings Products for Vulnerable Adolescent Girls show that the program was successful in build-

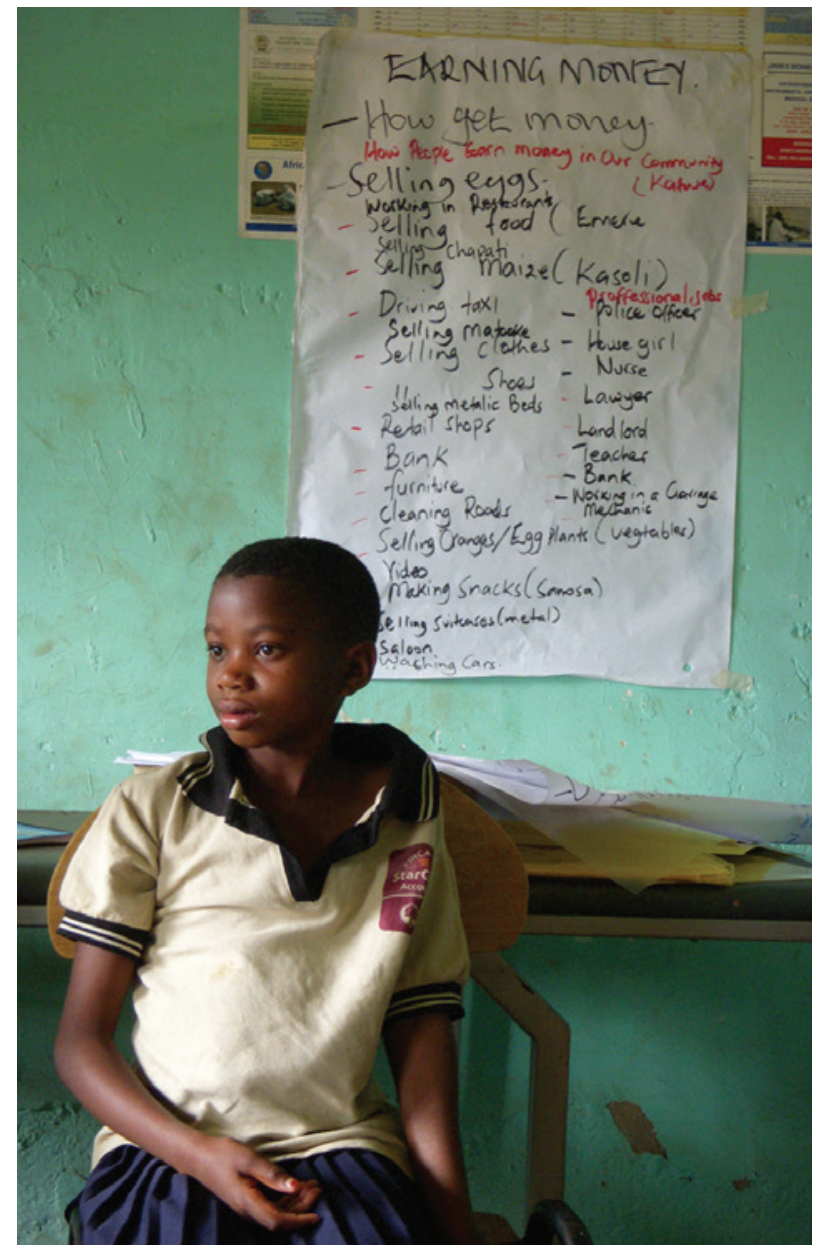

ing girls' social assets, providing critical reproductive health information, and empowering girls with financial skills and economic assets. At the end of the program, girls reported that they had made new friends, a safe space to meet with friends, and a female mentor they could go to for guidance. Girls who participated in the program showed significant improvements in access to emergency resources, increased mobility and increased independence. The importance of social networks and support was illustrated by comparing girls in Uganda who participated in Safe Spaces Group meetings with girls who did not. Girls who only had a savings account but did not receive reproductive health information and the social support associated with being part of a group were at increased risk of experiencing sexual harassment and exploitation. On the other hand, girls who participated in all program components were protected from sexual violence and showed significant improvements in reproductive health knowledge. Girls also provided anecdotal evidence about how their economic assets enabled them to become more economically independent and less likely to accept money from men in exchange for sexual favors. These findings support the asset building theory that girls need a combination of social, health and economic assets, and that increasing a girl's economic 
assets, without accompanying social support, skills, and self-esteem, can actually increase her vulnerability.

Overall, the savings product provided girls with a safe and reliable option for saving money. When combined with financial education regarding the importance of saving, girls began saving money and showed significant increases in saving between baseline and endline. The evaluation shows that girls used their savings to reduce vulnerability during emergencies. On the other hand, some girls reported that they were saving for future needs and goals, including education and plans to start their own businesses.

Since the pilot phase, the program has been expanded to reach over 12,000 girls in Kenya and Uganda. While there have been adjustments to the administrative structure, the program continues to be based on the asset building framework, providing the core components of savings, safe spaces groups, financial education and reproductive health information. The evidence from this evaluation supports the effectiveness of this model in building girls' assets, particularly for vulnerable girls residing in informal settlements. Additional research is needed to understand the feasibility of implementing a similar program in other areas, including rural and periurban settings. For policy, it would be helpful to know which combination of program components has the greatest effect on well-being. However, considering findings from Uganda, future studies testing the effect of increased economic assets must ensure that girls receive adequate social support so as not to increase their risks. Further studies are needed to understand the relationship between economic assets and the risk of sexual exploitation, as well as the protective factors that can mitigate these risks. The main limitation of this evaluation is the short time-period (one year), which limits the ability to observe significant changes in behaviors. Studies with a longer follow-up period would be instrumental in documenting the impact of this type of program on social, health and economic outcomes. 
www.popcouncil.org 